\title{
Biohydrogen production from arabinose and glucose using extreme thermophilic anaerobic mixed cultures
}

Angela A Abreu ${ }^{1,2}$, Dimitar Karakashev ${ }^{2}$, Irini Angelidaki ${ }^{2}$, Diana Z Sousa ${ }^{1}$ and M Madalena Alves ${ }^{1 *}$

\begin{abstract}
Background: Second generation hydrogen fermentation technologies using organic agricultural and forestry wastes are emerging. The efficient microbial fermentation of hexoses and pentoses resulting from the pretreatment of lingocellulosic materials is essential for the success of these processes.

Results: Conversion of arabinose and glucose to hydrogen, by extreme thermophilic, anaerobic, mixed cultures was studied in continuous $\left(70^{\circ} \mathrm{C}, \mathrm{pH} 5.5\right)$ and batch $\left(70^{\circ} \mathrm{C}, \mathrm{pH} 5.5\right.$ and $\left.\mathrm{pH} 7\right)$ assays. Two expanded granular sludge bed (EGSB) reactors, $R_{\text {arab }}$ and $R_{\text {gluc, }}$ were continuously fed with arabinose and glucose, respectively. No significant differences in reactor performance were observed for arabinose and glucose organic loading rates (OLR) ranging from 4.3 to $7.1 \mathrm{kgCOD} \mathrm{m} \mathrm{d}^{-1}$. However, for an OLR of $14.2 \mathrm{kgCOD} \mathrm{m}^{-3} \mathrm{~d}^{-1}$, hydrogen production rate and hydrogen yield were higher in $R_{\text {arab }}$ than in $R_{\text {gluc }}$ (average hydrogen production rate of 3.2 and $2.0 \mathrm{LH}_{2} \mathrm{~L}^{-1} \mathrm{~d}^{-1}$ and hydrogen yield of 1.10 and $0.75 \mathrm{molH}_{2} \mathrm{~mol}^{-1}$ substrate for $R_{\text {arab }}$ and $R_{\text {gluc, }}$ respectively). Lower hydrogen production in $R_{\text {gluc }}$ was associated with higher lactate production. Denaturing gradient gel electrophoresis (DGGE) results revealed no significant difference on the bacterial community composition between operational periods and between the reactors. Increased hydrogen production was observed in batch experiments when hydrogen partial pressure was kept low, both with arabinose and glucose as substrate. Sugars were completely consumed and hydrogen production stimulated (62\% higher) when pH 7 was used instead of pH 5.5 .

Conclusions: Continuous hydrogen production rate from arabinose was significantly higher than from glucose, when higher organic loading rate was used. The effect of hydrogen partial pressure on hydrogen production from glucose in batch mode was related to the extent of sugar utilization and not to the efficiency of substrate conversion to hydrogen. Furthermore, at pH 7.0, sugars uptake, hydrogen production and yield were higher than at $\mathrm{pH} 5.5$, with both arabinose and glucose as substrates.
\end{abstract}

Keywords: biohydrogen, extreme thermophilic conditions, arabinose, hydrogen partial pressure, $\mathrm{pH}$, lactate

\section{Background}

Hydrogen is a promising renewable energy carrier that can contribute towards a low carbon economy. Fermentative hydrogen production from carbohydrate-containing feedstock, such as glucose, sucrose and starch, has been extensively studied $[1,2]$. However, second generation hydrogen fermentation technologies are presently emerging as promising and more cost-effective solutions $[1,3]$.

\footnotetext{
* Correspondence: madalena.alves@deb.uminho.pt

${ }^{1}$ Institute for Biotechnology and Bioengineering, Centre of Biological

Engineering, University of Minho, 4710-057 Braga, Portugal

Full list of author information is available at the end of the article
}

Lignocellulosic material must be pre-treated prior to fermentation to hydrogen in order to remove lignin and hemicelluloses, reduce the cellulose crystallinity and increase the surface area of the material to enhance the release of sugars [4]. Physico-chemical pre-treatment of lignocellulosic material, such as the application of acid, alkaline or oxidative conditions at ambient or elevated temperatures, yields a mixture of pentoses and hexoses [1]. Efficient microbial fermentation of hexoses and pentoses is, therefore, the key step for hydrogen production from plant biomass. However, combined fermentation of mixtures of hexoses and
C Bïomed Central 
pentoses is often prevented due to catabolic repression; in the presence of glucose, pentoses might be converted to a lesser extent thereby decreasing overall fermentation yields [5,6]. Moreover, efficient hydrogen production from sugars is dependent on the different possible fermentation pathways (Figure 1).

Most of the extreme thermophiles from the phylum Clostridia use the Embden-Meyerhof pathway to metabolize hexose sugars to pyruvate [9]. Biohydrogen can be then formed via decarboxylation of pyruvate to acetyl $\mathrm{CoA}$, in which reduced ferredoxin $\left(\mathrm{Fd}_{\mathrm{red}}\right)$ is generated and acts as a direct electron donor for proton reduction to hydrogen (Figure 1). Maximum hydrogen yield, both from hexoses or pentoses, is obtained with acetate as the fermentation product (equations 1 and 2). Low yields are associated with the formation of more reduced end products compared to acetate, such as butyrate, propionate and alcohols (ethanol, butanol) and lactic acid.

$$
\begin{aligned}
& \mathrm{C}_{6} \mathrm{H}_{12} \mathrm{O}_{6}+2 \mathrm{H}_{2} \mathrm{O} \rightarrow 2 \mathrm{CH}_{3} \mathrm{COO}^{-}+2 \mathrm{CO}_{2}+2 \mathrm{H}^{+}+4 \mathrm{H}_{2} \\
& \mathrm{C}_{5} \mathrm{H}_{10} \mathrm{O}_{5}+1.67 \mathrm{H}_{2} \mathrm{O} \rightarrow 1.67 \mathrm{CH}_{3} \mathrm{COO}^{-}+1.67 \mathrm{CO}_{2}+1.67 \mathrm{H}^{+}+3.33 \mathrm{H}_{2}
\end{aligned}
$$

Environmental parameters such as $\mathrm{pH}$, hydrogen partial pressure and temperature have been documented as key factors in hydrogen fermentation [10]. The $\mathrm{pH}$ of the medium is known to regulate the shift to solventogenesis during the fermentation of sugars [7]; the effect of low $\mathrm{pH}$ in the inhibition of methanogenic archaea is also recognized and could be potentially used as a selective pressure in mixed culture systems. Metabolic pathways of hydrogen formation are sensitive to hydrogen partial pressure $\left(\mathrm{PH}_{2}\right)$ and are subject to end-product inhibition $[11,12]$. In addition, fermentation processes operating under thermophilic $\left(45\right.$ to $\left.60^{\circ} \mathrm{C}\right)$ and extreme thermophilic $\left(65\right.$ to $\left.80^{\circ} \mathrm{C}\right)$ could possibly result in higher hydrogen yields due to favorable thermodynamics and lower variety in soluble by-products [13]. High temperatures inhibit

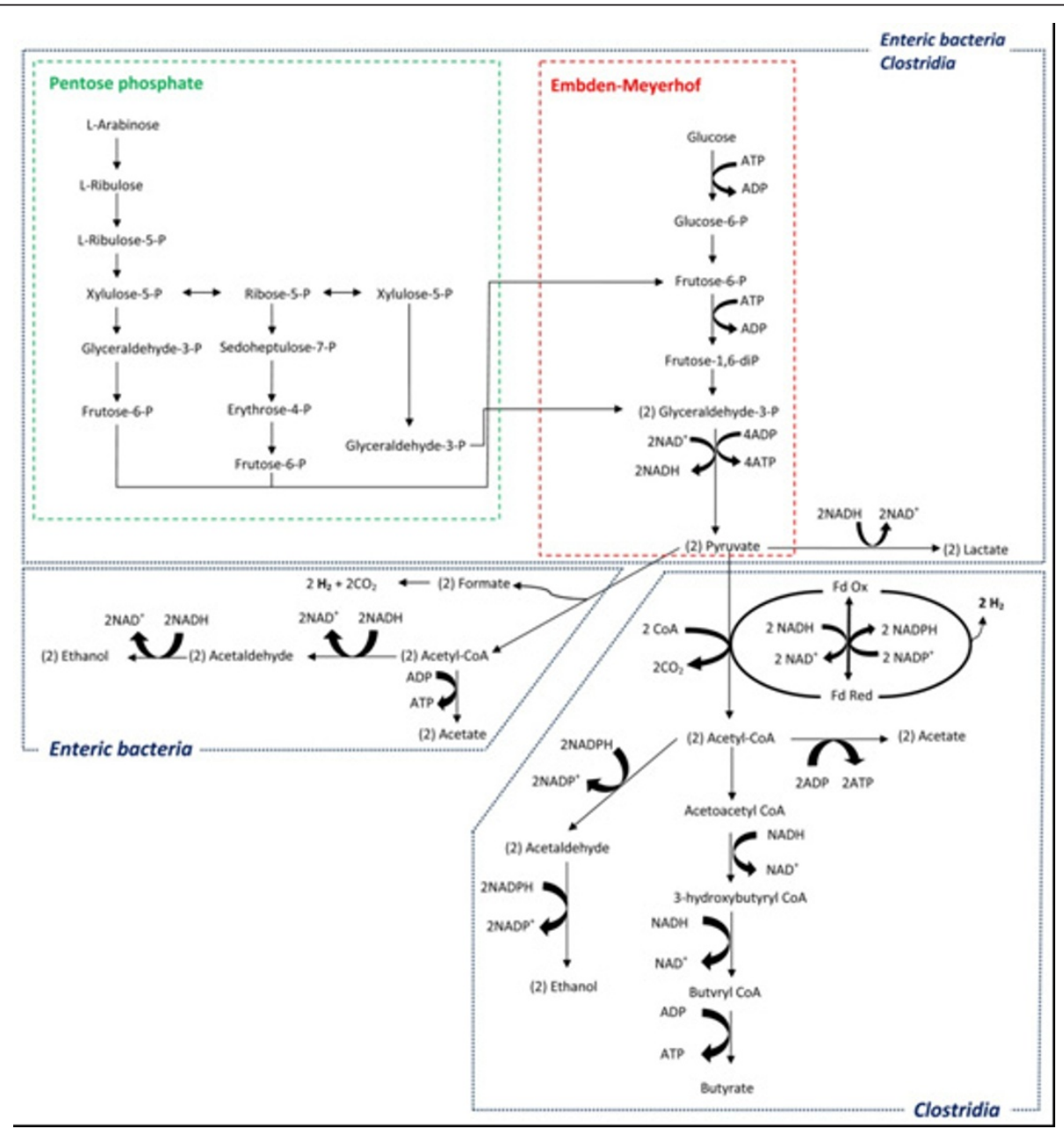

Figure 1 Major metabolic pathways for glucose and arabinose fermentation in mixed cultures (adapted from $[7,8]$ ). 
the growth of methanogenic archaea and homoacetogenic bacteria [13]; this is an important advantage when using mixed-cultures for hydrogen production because it prevents consumption of hydrogen by these microbial groups (as is often the case in mesophilic fermentation). Also, higher hydrolysis rates of cellulosic material have been observed in studies performed under thermophilic conditions, with the concurrent formation of higher amounts of fermentable sugars [14]. Hydrogen production by mixed culture fermentation is more suited for industrial applications, when compared to pure culture fermentation. Some of the advantages are: (i) no need for sterile cultivation, (ii) presence of high microbial diversity, which offers increased adaptation capacity, (iii) possibility of mixed substrates co-fermentation, and (iv) higher capacity for continuous processing $[15,16]$. However, and although there is a considerable number of studies on $\mathrm{H}_{2}$ production at extreme thermophilic conditions using pure cultures, studies using mixed-cultures are lacking $[17,18]$. Also, the effect of $\mathrm{pH}$ and hydrogen partial pressure has been described in several pure cultures of thermophiles and extreme-thermophiles but the effect in mixed cultures is not yet clear [17].

In the present study, the conversion of a C5-sugar (arabinose) and a C6-sugar (glucose) to hydrogen, using anaerobic mixed-cultures under extreme thermophilic conditions $\left(70^{\circ} \mathrm{C}\right)$, was studied in continuous expanded granular sludge bed (EGSB) reactors. Microbial diversity in arabinose- and glucose-fed bioreactors was assessed using a PCR-DGGE (denaturing gradient gel electrophoresis) approach. Additional batch experiments were performed with extreme-thermophilic mixed cultures to study the effect of hydrogen partial pressure and $\mathrm{pH}$ on hydrogen production from arabinose and glucose.

\section{Results}

\section{EGSB reactors performance}

Hydrogen production rates in arabinose- and glucose-fed reactors $\left(R_{\text {arab }}\right.$ and $\left.R_{\text {gluc }}\right)$ are shown in Figures 2 and 3, respectively. Only $\mathrm{H}_{2}$ and $\mathrm{CO}_{2}$ were detected in the gas phase; methane was not produced during all operation time. During start-up (period I), hydrogen production rates of approximately $0.3 \mathrm{~L} \mathrm{H}_{2} \mathrm{~L}^{-1} \mathrm{~d}^{-1}$ were observed in both reactors. This corresponds to hydrogen yields of roughly 0.2 and $0.3 \mathrm{~mol} \mathrm{H}_{2}$ per mol of substrate consumed, for $R_{\text {arab }}$ and $R_{\text {gluc }}$ respectively (Table 1$)$. In period II, the increase in arabinose and glucose inlet concentration to $16.6 \mathrm{mM}$ and $13.8 \mathrm{mM}$, respectively, resulted in hydrogen yields of about $0.80 \mathrm{~mol} \mathrm{H}_{2}$ per mole of substrate in both $R_{\text {arab }}$ and $R_{\text {gluc }}$ (Table 1). Maximum hydrogen production rates in period II were of $1.36 \pm 0.04$ and $1.12 \pm 0.07 \mathrm{LH}_{2} \mathrm{~L}^{-1} \mathrm{~d}^{-1}$ in $\mathrm{R}_{\text {arab }}$ and $\mathrm{R}_{\text {gluc }}$, respectively. Substrate was completely consumed in both reactors and the main by-products formed were butyrate, acetate and lactate (Figures 2 and 3). In operation period III, substrate concentrations fed to $R_{\text {arab }}$ and $R_{\text {gluc }}$ were increased to $33.3 \mathrm{mM}$ of arabinose and $27.7 \mathrm{mM}$ of glucose, respectively. As a result of this increase, there was a temporary raise in arabinose/glucose concentration in the effluent but, after 13 days of acclimation to the higher substrate loads, virtually all glucose and an average of $79 \%$ arabinose were used in the reactors (Table 1) Steady state hydrogen production rates of $3.26 \pm 0.16$ and $2.06 \pm$ $0.06 \mathrm{~L} \mathrm{H}_{2} \mathrm{~L}^{-1} \mathrm{~d}^{-1}$ were observed in $\mathrm{R}_{\text {arab }}$ and $\mathrm{R}_{\text {gluc }}$, respectively (Figures 2 and 3). During period III, $R_{\text {gluc }}$ showed a stable hydrogen yield of about $0.75 \mathrm{~mol} \mathrm{H}_{2}$ per mole of substrate consumed. Hydrogen yield in $\mathrm{R}_{\mathrm{arab}}$ was significantly higher, that is. $1.10 \mathrm{~mol} \mathrm{H}_{2}$ per mole of substrate consumed. Lactate concentration in $\mathrm{R}_{\text {gluc }}$ increased sharply during period III of operation reaching values of approximately $20 \mathrm{mM}$ (Figure 3 ). An increase in lactate concentration was also observed in $\mathrm{R}_{\mathrm{arab}}$, but did not exceed $11 \mathrm{mM}$ (Figure 2). Estimation of the theoretical reduced form of nicotinamide adenine dinucleotide $(\mathrm{NADH})$ production from glucose and arabinose, considering the main catabolic pathways (that is, EmbdenMeyerhof for glucose and a combination of pentose phosphate and Embden-Meyerhof pathways for arabinose (Figure 1)), demonstrates that a higher reducing power was potentially formed in $\mathrm{R}_{\text {gluc }}$ than in $\mathrm{R}_{\mathrm{arab}}$. Estimated NADH concentration in $R_{\text {gluc }}$ was $42 \mathrm{mM}$ after three days of operation, while in $R_{\text {arab }}$ was $37 \mathrm{mM}$ after five days of operation.

\section{Bacterial community composition dynamics in EGSB reactors}

DGGE profiles generated for sludge samples withdrawn from $R_{\text {arab }}$ and $R_{\text {gluc }}$ (Figure 4) show that bacterial composition in both reactors' sludge at the end of periods II (Day 27) and III (Day 41) are identical. Differences in substrate composition did not affect the bacterial community in reactors $R_{a r a b}$ and $R_{\text {gluc }}$ and similarity index between Arab/Gluc samples at the end of the operation was as high as $94 \%$. Predominant DGGE bands in $R_{\text {gluc }}$ and $R_{a r a b}$ were identical to the ones present in the inoculum used in this study and for which the phylogeny had been previously assessed [6]. Two of the predominant DGGE bands showed high similarity (> 99\%) with the hydrogen-producing Thermoanaerobacterium thermosaccharolyticum. Members of the Klebsiella, Bacillus and Sporolactobacillus genera, detected in the inoculum sludge, were also predominant in $R_{\text {gluc }}$ and $R_{\text {arab }}$.

\section{Effect of hydrogen partial pressure and $\mathrm{pH}$ on batch hydrogen production from arabinose and glucose} The effect of the hydrogen partial pressure, while using arabinose and glucose as substrates, was studied in batch experiments at $\mathrm{pH} 5.5$ (equivalent to $\mathrm{pH} 5.0$ at 


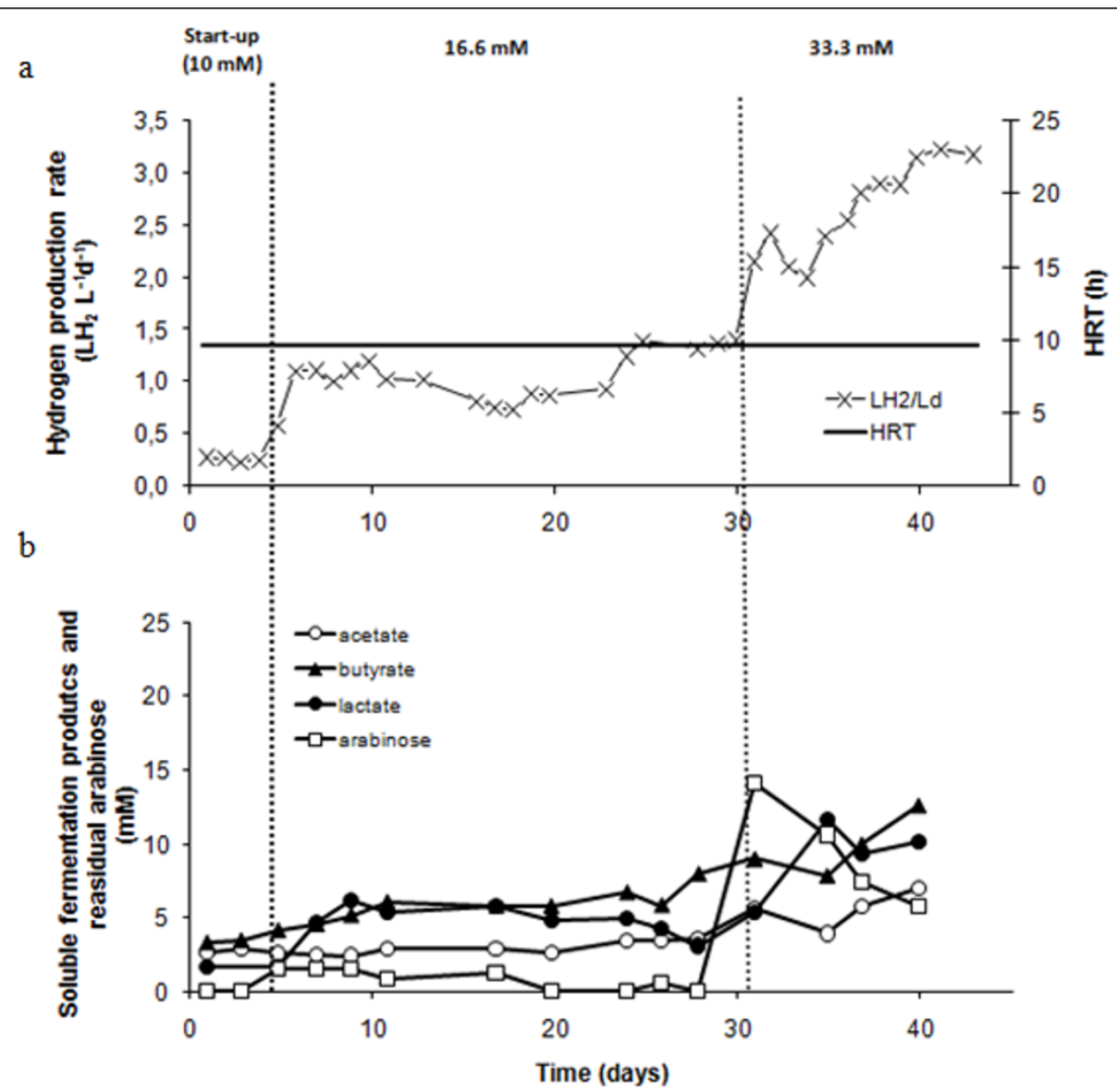

Figure 2 Effect of OLR on performance of $R_{\text {arab }}$ (a) hydrogen production rate and HRT, (b) soluble fermentation products and residual arabinose.

$70^{\circ} \mathrm{C}$ ). Assays were performed allowing the accumulation of hydrogen in the headspace (no headspace flushing, NHF), or preventing hydrogen accumulation in the headspace (headspace flushing, HF). Subsequently, HF assays were performed at $\mathrm{pH} 7.0$ (that is, $\mathrm{pH} 6.5$ at $70^{\circ} \mathrm{C}$ ) to study the effect of $\mathrm{pH}$ increase in hydrogen production. Substrates were added at the beginning of the experiment and a second addition was performed after complete depletion of the first load.

In the NHF ( $\mathrm{pH} 5.5)$, maximum hydrogen concentration in the gas was achieved 44 and $20 \mathrm{~h}$ after the second addition of arabinose or glucose addition, respectively (Figure 5a, b). At this point, hydrogen partial pressure in both arabinose and glucose assays was roughly $1.2 \times 10^{4} \mathrm{~Pa}\left(\right.$ at $\left.70^{\circ} \mathrm{C}\right)$, which corresponds to a dissolved hydrogen concentration of $105 \mu \mathrm{M}$. From this point on, hydrogen production was not significant, even though only $35 \%$ of arabinose and $13 \%$ of glucose were present at the end of the experiment. Identical hydrogen yield, that is, $0.7 \mathrm{~mol} \mathrm{H}_{2}$ per mole of substrate, was obtained for NHF arabinose and glucose experiments (Table 2).
Hydrogen production from arabinose could be increased in assays in which hydrogen partial pressure in the headspace was kept low (HF). A cumulative hydrogen production of 1 . To $-1.7 \times 10^{4} \mathrm{~Pa}\left(\right.$ at $\left.70^{\circ} \mathrm{C}\right)$ was attained in $\mathrm{HF}$ ( $\mathrm{pH} 5.5$ ) arabinose experiments (Figure 5c). This value is significantly higher than the one obtained in NHF experiments ( $P<0.01$ : $t$-test), and corresponds to an increase of about $40 \%$ in hydrogen pressure. However, the highest increment in hydrogen cumulative production (that is, 62\%) was observed in HF arabinose assays performed at $\mathrm{pH} 7.0$ (cumulative hydrogen pressure of $2.8 \times 10^{4} \mathrm{~Pa}$ at $70^{\circ} \mathrm{C}$ (Figure 5f)). Arabinose was totally consumed in HF assays at $\mathrm{pH}$ 7.0, while a fraction substrate (approximately 1\%) was not used in HF assays at pH 5.5 (Figure 5c, e). Nevertheless, non-consumed arabinose in $\mathrm{HF}$ at $\mathrm{pH} 5.5$ was considerably lower than in NHF assays (Figure 5a, c). Hydrogen yields in HF arabinose experiments at $\mathrm{pH} 5.5$ and $\mathrm{pH} 7.0$ were 0.76 and $1.15 \mathrm{~mol} \mathrm{H}_{2}$ per mole of substrate consumed, respectively (Table 2).

Hydrogen production values in HF and NHF glucose experiments at pH 5.0 were not significantly different. 


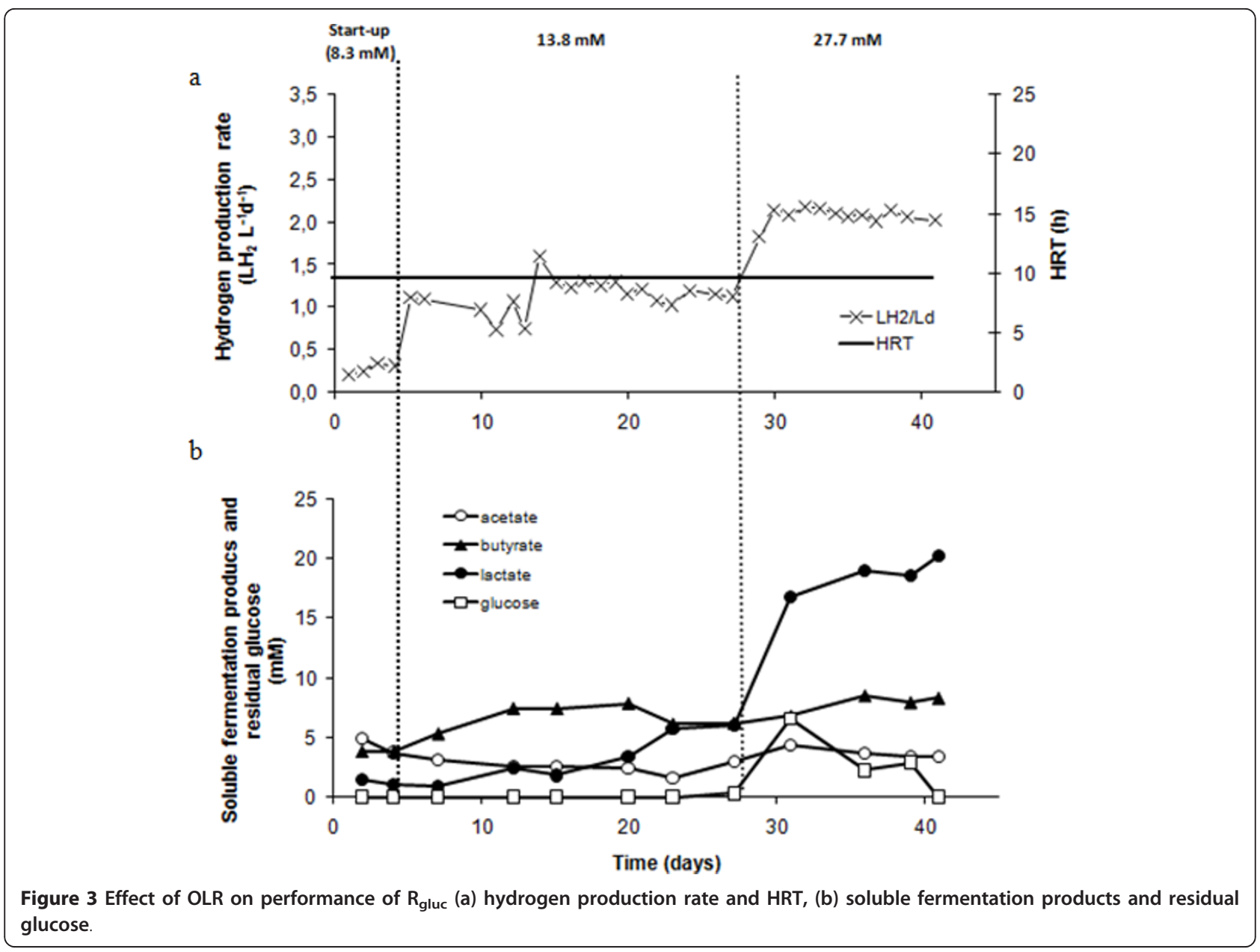

However, cumulative hydrogen production from glucose in HF experiments at $\mathrm{pH} 7.0$ was significantly higher $(P$ $<0.001$ : $t$-test) than at pH 5.5 (Figure $5 \mathrm{~d}, \mathrm{f}$ ). Hydrogen cumulative pressure in HF glucose assays at $\mathrm{pH} 7$ was of $2.6 \times 10^{4} \mathrm{~Pa}\left(\right.$ at $70^{\circ} \mathrm{C}$, Figure $5 \mathrm{f}$ ). Glucose was totally consumed in $\mathrm{HF}$ assays both at $\mathrm{pH} 5.5$ and $\mathrm{pH}$ 7.0.

Table 1 Process performance of $\mathbf{R}_{\text {arabr }}, \mathbf{R}_{\text {gluc }}$ and $\mathbf{R}_{\text {gluc }+a r a b}$.

\begin{tabular}{|c|c|c|c|c|c|c|c|c|}
\hline & $\begin{array}{c}\text { Feed } \\
\text { concentration } \\
(\mathrm{mM})\end{array}$ & $\begin{array}{c}\text { Glucose } \\
\text { utilization } \\
(\%)\end{array}$ & $\begin{array}{c}\text { Arabinose } \\
\text { utilization } \\
\text { (\%) }\end{array}$ & $\begin{array}{l}\text { Hydrogen yield } \\
\left(\text { molH }_{2} \text { mol }\right. \\
\text { substrate } \\
\left.\text { consumed }^{-1}\right)\end{array}$ & $\begin{array}{l}\text { Percentage of } \mathrm{H}_{2} \\
\text { produced from the } \\
\text { theoretical yield } \\
(\%)\end{array}$ & $\begin{array}{c}\text { Hydrogen } \\
\text { production } \\
\text { rate } \\
\left(\mathrm{LH}_{2} \mathrm{~L}^{-1} \mathrm{~d}^{-1}\right)\end{array}$ & $\begin{array}{c}\text { COD } \\
\text { balance } \\
(\%)^{*}\end{array}$ & Reference \\
\hline \multirow{3}{*}{$\begin{array}{l}\text { Glucose } \\
\text { reactor } \\
\left(\mathrm{R}_{\text {gluc }}\right)\end{array}$} & 8.3 & 100 & na & $0.34 \pm 0.05$ & 8 & $0.32 \pm .018$ & 96 & This study \\
\hline & 13.8 & 100 & na & $0.80 \pm 0.03$ & 20 & $1.15 \pm 0.04$ & 94 & \\
\hline & 27.7 & 100 & na & $0.75 \pm 0.07$ & 19 & $2.10 \pm 0.06$ & 99 & \\
\hline \multirow{3}{*}{$\begin{array}{l}\text { Arabinose } \\
\text { reactor } \\
\left(\mathbf{R}_{\text {arab }}\right)\end{array}$} & 10.0 & na & 100 & $0.23 \pm 0.01$ & 7 & $0.24 \pm 0.01$ & 113 & This study \\
\hline & 16.6 & na & 99 & $0.77 \pm 0.02$ & 23 & $1.36 \pm 0.04$ & 97 & \\
\hline & 33.3 & na & 79 & $1.10 \pm 0.01$ & 33 & $3.26 \pm 0.16$ & 112 & \\
\hline $\begin{array}{c}\text { Glucose }+ \\
\text { Arabinose } \\
\text { Reactor }\left(\mathbf{R}_{\text {gluc }}\right. \\
\text { +arab }\end{array}$ & $13.8+16.6$ & 100 & 75 & $0.77 \pm 0.05$ & - & $2.36 \pm 0.14$ & 109 & [6] \\
\hline
\end{tabular}




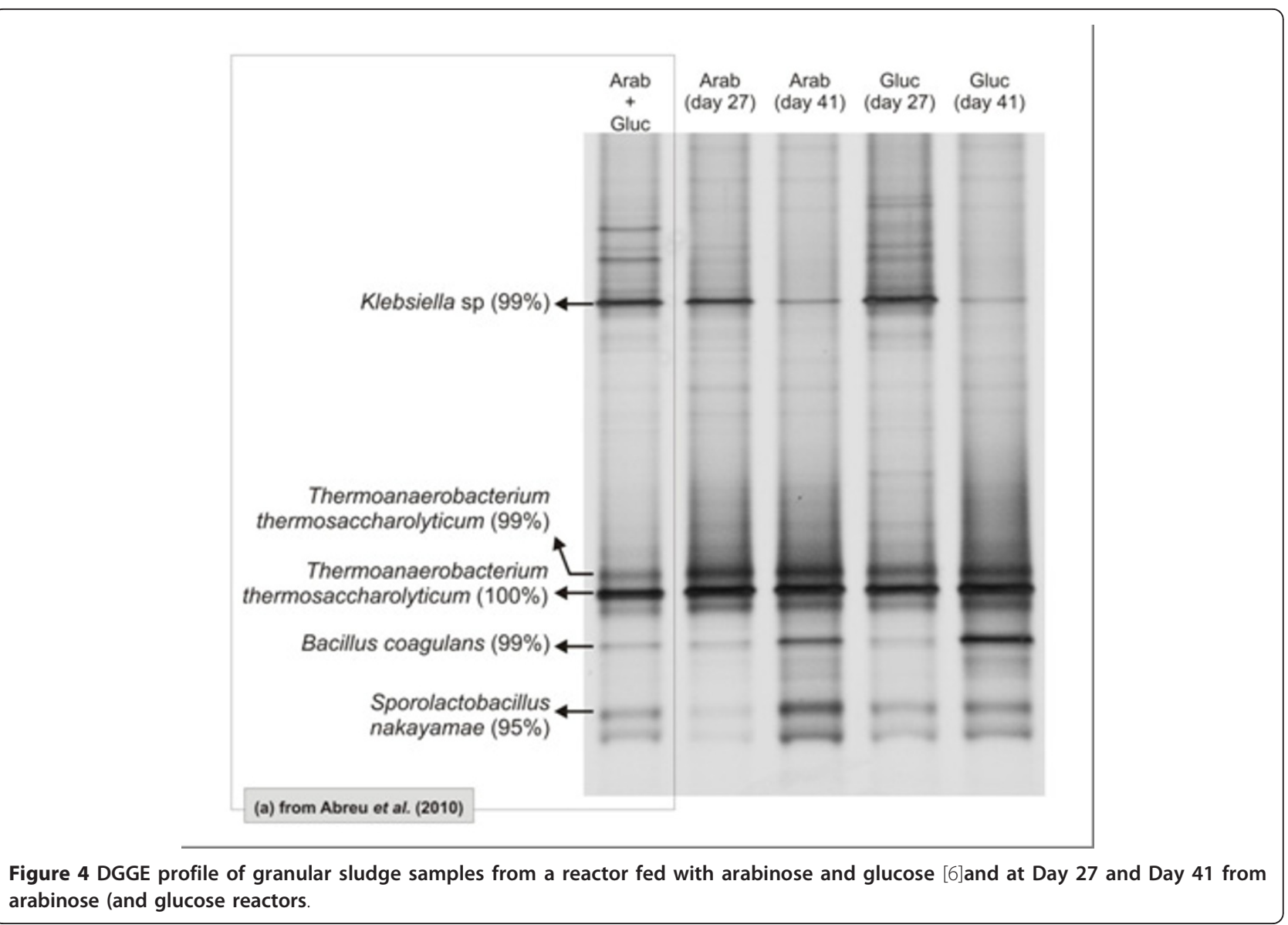

Hydrogen yields in $\mathrm{HF}$ glucose experiments at $\mathrm{pH} 5.5$ and $\mathrm{pH} 7.0$ were 0.6 and $1.4 \mathrm{~mol} \mathrm{H}_{2}$ per mole of substrate consumed, respectively (Table 2 ).

At pH 5.5 approximately $20 \mathrm{mM}$ of ethanol was produced from both substrates. At $\mathrm{pH} 7$ ethanol formation did not exceed $15 \mathrm{mM}$ (Figure 6). Acetate formation from both substrates at $\mathrm{pH} 7$ achieved approximately 14 $\mathrm{mM}$ (Figure 6). In the case of glucose a decrease in $40 \%$ of lactate formation was also observed in incubations at $\mathrm{pH} 7$.

\section{Discussion}

\section{Continuous hydrogen production in EGSB reactors}

$R_{\text {arab }}$ and $R_{\text {gluc }}$ showed similar performance during periods I and II of operation. However, when a higher organic loading rate was applied to the reactors (period III of operation, arabinose and glucose concentrations of 33.3 and 27.7, respectively), $R_{\text {arab }}$ showed a steady state hydrogen production rate $1.6 \times$ higher than $R_{\text {gluc }}$. Furthermore, hydrogen production rate measured in $\mathrm{R}_{\mathrm{arab}}$ was $1.3 \times$ higher than the one reported by Abreu et al. [6] when feeding a EGSB reactor with a mixture of arabinose and glucose (1/1). Hydrogen production yield in $R_{\text {arab }}$ was $1.10 \mathrm{~mol} \mathrm{H}_{2}$ per mole of arabinose consumed, which is considerably higher than the yields obtained in $\mathrm{R}_{\text {gluc }}$ (0.75 $\mathrm{mol} \mathrm{H}_{2}$ per mole of glucose) and $\mathrm{R}_{\text {gluc }+ \text { arab }}(0.77 \mathrm{~mol}$ $\mathrm{H}_{2}$ per mole glucose + arabinose) (Table 1). According to these results, the presence of glucose may possibly decrease the overall hydrogen yield in continuous operation, particularly when higher organic loading rates are applied. Lower hydrogen production observed in $\mathrm{R}_{\text {gluc }}$ was likely associated with high lactate production (Figure 3). According to the Embden-Meyerhof pathway (Figure 1), sugar-derived pyruvate is (1) reduced to lactate, with regeneration of NADH (Table 3, reaction 1), or (2) oxidized to acetyl-CoA, with the production of reduced ferredoxin (Table 3 reaction (2)). Reaction (1) does not yield hydrogen, while in reaction (2) one mol of pyruvate results in the formation of $2 \mathrm{~mol}$ hydrogen. However, and considering Gibbs energy variations, reaction (1) seems to be energetically more favorable than reaction (2), especially at higher hydrogen partial pressures (Table 3).

The fact that the microbial communities' composition in the reactors did not change along the three operational periods (Figure 4), suggests that the higher concentration of lactate produced in $\mathrm{R}_{\text {gluc }}$ during period III is related to metabolic changes and is not a consequence of bacterial community shifts. Two of the predominant DGGE bands 


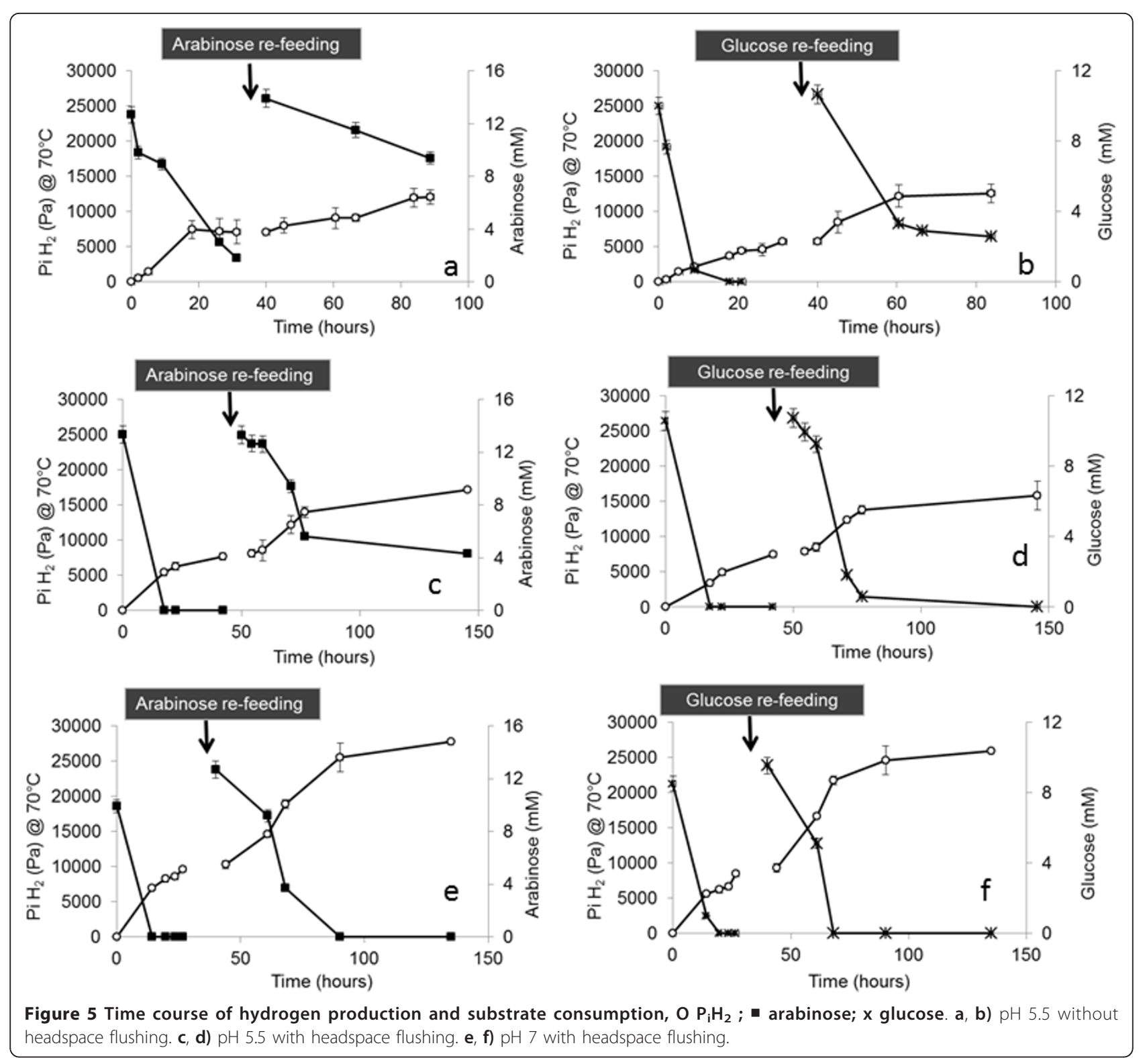

Table 2 Substrate consumption and hydrogen yields from batchexperiments.

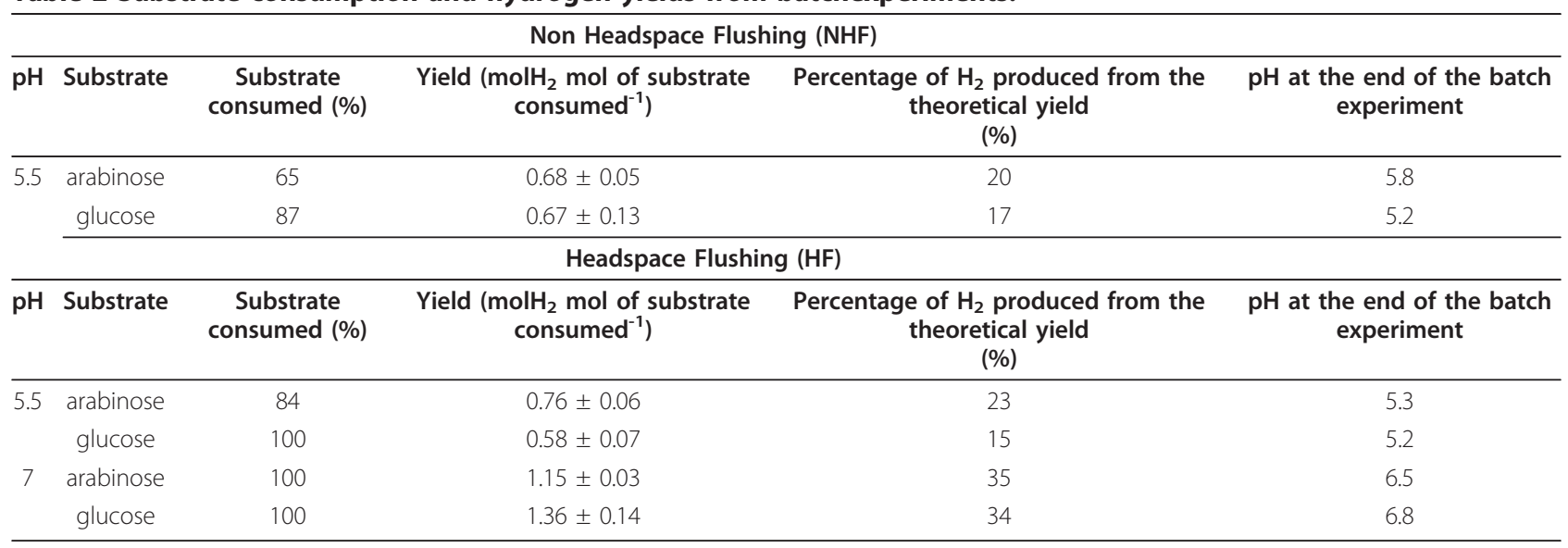



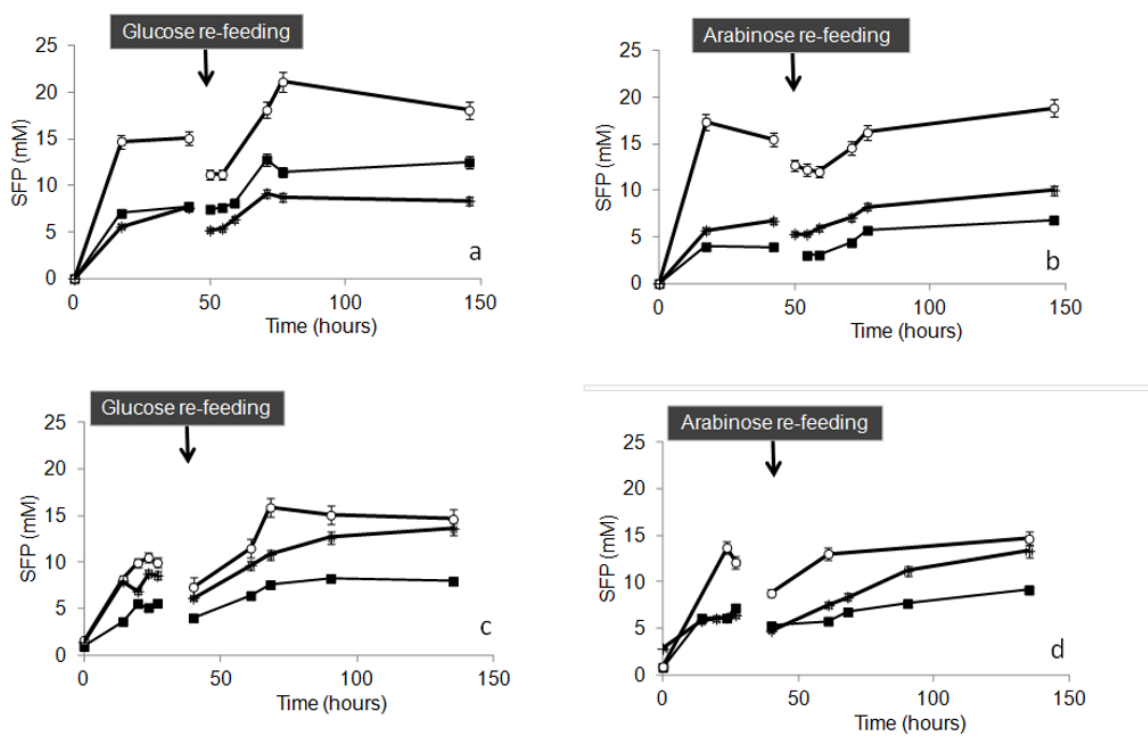

Figure 6 Time course of soluble fermentation products, $\mathbf{O}$ ethanol; lactate; + acetate. a, b) pH 5.5 with headspace flushing. $\mathbf{c}$, d) $\mathrm{pH} 7$ with headspace flushing.

present in the reactors sludge could be affiliated with Thermoanaaerobacterim thermosacharolyticum (similarity higher than 99\%). A draft genome of T. thermosacharolyticum (Joint Genome Institute) allowed a search of genes that encode metabolic enzymes involved in pyruvate conversion. A L-lactate dehydrogenase (EC 1.1.1.27) was present indicating the possibility of pyruvate reduction to lactate. Some genes codifying subunits of enzymes related to pyruvate-ferredoxin oxidoreductases and NADH oxidoreductases were also found but a complete picture of the mechanisms involved in pyruvate conversion to acetyl-CoA cannot be retrieved. Clones corresponding to other predominant DGGE bands present in reactors sludge exhibited highest sequence identity with Klebsiella sp. (99\%) and Bacillus coagullans (99\%). All these microorganisms are able to produce hydrogen and lactate, among other products, from a variety of carbon sources [21-23]. No genomic information is available for these species and physiological information is sometimes contradictory. For instance, the presence of Bacillus

Table 3 Gibbs free energy changes for some of the glucose and arabinose oxidation reactions.

\begin{tabular}{|c|c|c|c|}
\hline Equation & & $\begin{array}{c}\Delta \mathrm{G}^{0, a} a \\
\left(\mathrm{~kJ} \text { reaction }^{-1} \text { ) }\right.\end{array}$ & $\begin{array}{c}\Delta \mathrm{G}^{\prime b} \\
\left(\mathrm{~kJ} \text { reaction }^{-1}\right)\end{array}$ \\
\hline \multicolumn{4}{|l|}{ Fermentative reactions } \\
\hline $\mathrm{NADH}+\mathrm{H}^{+}+$pyruvate $^{-} \rightarrow \mathrm{NAD}^{+}+$lactate $^{-}$ & (1) & -25 & \\
\hline 2 ferredoxin $($ red $)+2 \mathrm{H}^{+} \rightarrow 2$ ferredoxin $(\mathrm{ox})+\mathrm{H}_{2}$ & (2) & +3 & -25 \\
\hline \multicolumn{4}{|l|}{ Glucose oxidation reactions } \\
\hline 1 glucose $+2 \mathrm{H}_{2} \mathrm{O} \rightarrow 2$ acetate ${ }^{-}+2 \mathrm{CO}_{2}+2 \mathrm{H}^{+}+4 \mathrm{H}_{2}$ & (3) & -216 & \\
\hline 1 glucose $\rightarrow 1$ butyrate ${ }^{-}+2 \mathrm{CO}_{2}+2 \mathrm{H}^{+}+2 \mathrm{H}_{2}$ & (4) & -264 & \\
\hline 1 glucose $\rightarrow 2$ lactate $+2 \mathrm{H}^{+}$ & (5) & -197 & \\
\hline 1 glucose $\rightarrow 2$ ethanol $^{-}+2 \mathrm{CO}_{2}+2 \mathrm{H}^{+}$ & (6) & -315 & \\
\hline \multicolumn{4}{|l|}{ Arabinose oxidation reactions } \\
\hline 1 arabinose $+1.67 \mathrm{H}_{2} \mathrm{O} \rightarrow 1.67$ acetate $^{-}+1.67 \mathrm{CO}_{2}+1.67 \mathrm{H}^{+}+3.33 \mathrm{H}_{2}$ & (7) & -192 & \\
\hline 1 arabinose $\rightarrow 0.83$ butyrate $^{-}+1.66 \mathrm{CO}_{2}+0.83 \mathrm{H}^{+}+1.66 \mathrm{H}_{2}$ & (8) & -228 & \\
\hline 1 arabinose $\rightarrow 1.66$ lactate $^{-}+1.66 \mathrm{H}^{+}$ & (9) & -172 & \\
\hline 1 arabinose $\rightarrow 1.66$ ethanol $^{-}+1.66 \mathrm{CO}_{2}+1.66 \mathrm{H}^{+}$ & (10) & -269 & \\
\hline
\end{tabular}

Standard Gibbs energies of formation of arabinose (in aqueous solution, $\mathrm{pH} 7$ and $25^{\circ} \mathrm{C}$ ) were estimated from the structures of the compounds, using a group contribution method described by [19]; standard Gibbs energies of formation of other compounds involved in the reactions were obtained from [20]

${ }^{a}$ Gibbs free energies (at $25^{\circ} \mathrm{C}$ ) calculated at standard conditions (solute concentrations of $1 \mathrm{M}$ and gas partial pressure of $10^{5} \mathrm{~Pa}$ ).

${ }^{b}$ Gibbs free energies (at $25^{\circ} \mathrm{C}$ ) calculated at standard conditions (solute concentrations of $1 \mathrm{M}$ and gas partial pressure of $1 \mathrm{~Pa}$ ). 
coagullans in hydrogen producing reactors has been associated to the increase of lactate production [24,25], but also to optimized hydrogen production $[23,26]$.

The main possible reactions for the fermentation of arabinose and glucose, and the calculated Gibbs free energy of global reactions are shown in Table 3 (equations (3) to (10)) (only the reactions yielding experimentally detected soluble fermentation products in $\mathrm{R}_{\text {gluc }}$ and $R_{\text {arab }}$ are represented). From a thermodynamic point of view, lactate formation from glucose and arabinose is less favorable than the formation of butyrate or ethanol. However, in continuous processes lactate was one of the main soluble fermentation products present in both reactors, especially in $R_{\text {gluc }}$ at higher influent, substrate concentration $(27.7 \mathrm{mM})$. This might be related to the need of recycling reducing power from NADH. It has been proposed that thermophiles usually possess some escape routes to dispose of reductants in order to prevent obstructions in their metabolic flux. A possible route for this is the production of more reduced organic compounds like lactate, acetone and butanol $[9,23]$. A switch to lactate formation in Thermoanaerobacterium sp. was observed as a mechanism of reductant disposal and $\mathrm{NAD}(\mathrm{P}) \mathrm{H}$ oxidation $[9,27]$.

\section{Hydrogen partial pressure and $\mathrm{pH}$ influence on hydrogen production yields}

The metabolic pathways of hydrogen formation are sensitive to hydrogen concentrations and are subject to end-product inhibition. Results from this study showed that hydrogen production from arabinose and glucose is indeed higher when hydrogen is not allowed to accumulate in the headspace. Keeping low hydrogen partial pressure caused an increase in hydrogen production that could be mainly related to enhanced sugar utilization under these conditions. Nevertheless, in arabinose assays substrate was never completely depleted, not even when hydrogen was removed from the headspace. This can indicate that limiting factors other than $\mathrm{PH}_{2}$, such as liquid by-products inhibition, might be involved in hydrogen production from arabinose.

It has been reported that thermophilic hydrogen producing microorganisms could be inhibited by the presence of hydrogen, even when at very low partial pressure (from $0.1 \times 10^{4}$ to $7.5 \times 10^{4} \mathrm{~Pa}$ ) [28]. Values of hydrogen partial pressure of $2 \times 10^{3} \mathrm{~Pa}, 1.6 \times 10^{3} \mathrm{~Pa}$ and $1.0 \times 10^{4} \mathrm{~Pa}$ were described as inhibitory for hydrogen production with Thermotoga maritima, Pyrococcus furiosus and Caldicellulosiruptor saccharolyticus, respectively [29]. In the present study hydrogen production by extreme thermophile mixed cultures using glucose and arabinose was inhibited at a $\mathrm{PH}_{2}$ similar to the one reported for C. saccharolyticus (that is, $1.2 \times 10^{4} \mathrm{~Pa}$ at $\left.70^{\circ} \mathrm{C}\right)$.
Higher cumulative hydrogen production and yields were obtained at $\mathrm{pH} 7.0$, either using glucose or arabinose as substrate. Lower hydrogen production at $\mathrm{pH} 5.5$ was coupled to high ethanol and low acetate production (Figure 6). The present study suggests that, at extreme thermophilic conditions, maintenance of neutral $\mathrm{pH}$ (around 6.5 at $70^{\circ} \mathrm{C}$ ) can aid preventing hydrogen losses by avoiding the production of more reduced organic compounds (such as lactic acid, acetone, butanol, and so on).

Overall, the results presented in this study show that both $\mathrm{pH}$ and hydrogen partial pressure affect hydrogen production efficiencies by extreme thermophilic mixed cultures. However, pH influenced hydrogen production in a greater extent than hydrogen partial pressure, both when using glucose or arabinose as substrate. Different soluble fermentation products' composition was observed in batch experiments and in continuous reactors. This can be related with the accumulation of soluble fermentation products happening in the batch assays, which can lead to different environmental conditions and, therefore, induce different metabolic pathways [30-32]. Nevertheless, batch results can give valuable insights for improving hydrogen production in continuous process.

\section{Conclusions}

In continuous reactor, hydrogen production rate from arabinose was significantly higher than from glucose, when using organic loading rates of $14 \mathrm{KgCOD} \mathrm{m}{ }^{-3} \mathrm{~d}^{-1}$. This fact was associated with higher lactate production in the reactor fed with glucose, while in the arabinosefed reactor, acetate and ethanol were the main end-products formed. The higher concentration of lactate was not a consequence of bacterial community shift, and is likely related to changes in the main metabolic pathways of glucose catabolism.

In batch mode, the effect of hydrogen partial pressure on hydrogen production from glucose was related to the extent of sugar utilization and not to the efficiency of substrate conversion to hydrogen. Furthermore, at $\mathrm{pH}$ 7.0, sugars uptake, hydrogen production and yield were higher than at $\mathrm{pH} 5.5$, with both arabinose and glucose as substrates.

\section{Methods}

\section{Continuous hydrogen production in EGSB reactors}

Experiments were carried out in two plexi-glass EGSB reactors. An arabinose reactor $\left(\mathrm{R}_{\mathrm{arab}}\right)$ and a glucose reactor $\left(R_{\text {gluc }}\right)$ were fed with $\mathrm{L}$-arabinose and glucose, respectively. EGSB reactors had a height of $1.95 \mathrm{~m}$ and internal diameter of $21 \mathrm{~mm}$. Total liquid volume was $1.30 \mathrm{~L}$, including reaction-zone volume of $0.7 \mathrm{~L}$. Reactors were operated at $70 \pm 1^{\circ} \mathrm{C}$ by means of an external 
water jacket, and $\mathrm{pH}$ inside the reactors was maintained at $5.5 \pm 0.5$. Superficial velocity was set at $10.0 \mathrm{~m} \mathrm{~h}^{-1}$ (using internal recirculation) with an hydraulic retention time (HRT) of $9 \mathrm{~h}$. Before start-up, $\mathrm{R}_{\text {arab }}$ and $\mathrm{R}_{\text {gluc }}$ were inoculated with $400 \mathrm{~mL}$ of granular sludge from a labscale hydrogen-producing reactor that had been fed with a mixture of arabinose $(17 \mathrm{mM})$ and glucose (14 $\mathrm{mM}$ ) for two months. Start-up of $R_{\text {arab }}$ was done using a constant arabinose feed concentration of $10.0 \mathrm{mM}$ (period I); afterwards, arabinose concentrations of 16.6 $\mathrm{mM}$ (period II) and $33.3 \mathrm{mM}$ (period III) were fed. Start-up of $R_{\text {gluc }}$ was done using a constant glucose feed concentration of $8.3 \mathrm{mM}$ (period I); afterwards, concentrations of $13.8 \mathrm{mM}$ (period II) and $27.7 \mathrm{mM}$ (period III) were tested (Table 4). Arabinose and glucose concentration differed in order to have identical theoretical hydrogen yields in both reactors (that is, 33.3, 55.5 and $110.8 \mathrm{mM} \mathrm{H}_{2}$ for periods I, II and III, respectively). Sodium bicarbonate was added to the feed as alkalinity source (at a final concentration of 1 to $2 \mathrm{~g} \mathrm{~L}^{-1}$ ). Macronutrients solution containing $30 \mathrm{~g} \mathrm{~L}^{-1} \mathrm{MgSO}_{4} .7 \mathrm{H}_{2} \mathrm{O}, 28.3$ $\mathrm{g} \mathrm{L}^{-1} \mathrm{KH}_{2} \mathrm{PO}_{4}$ and $\left.170 \mathrm{~g} \mathrm{~L}^{-1}\right) \mathrm{NH}_{4} \mathrm{Cl}$ was also added ( $0.6 \mathrm{~mL}$ macronutrients solution per $\mathrm{g}$ of chemical oxygen demand (COD) in the feed).

\section{Batch experiments}

\section{Seed sludge}

Granular sludge used for inoculating batch assays for studying arabinose- and glucose-conversion was collected from reactors $R_{\text {arab }}$ and $R_{\text {gluc }}$, respectively.

\section{Medium composition and substrates}

Assays were performed in $70 \mathrm{~mL}$ serum bottles containing $18 \mathrm{~mL}$ of buffered medium. Phosphate-buffered medium $(20 \mathrm{mM})$ and bicarbonate-buffered medium (Stams et al. 1993) were used for experiments at $\mathrm{pH} 5.5$ and $\mathrm{pH} 7$, respectively. Bottles with phosphate-buffered medium were flushed with $\mathrm{N}_{2}(100 \%)$, while bottles with bicarbonate-buffered medium were equilibrated with a mixture of $\mathrm{N}_{2}: \mathrm{CO}_{2} \quad(80: 20 \%)$. Both media were

\begin{tabular}{|c|c|c|}
\hline \multicolumn{3}{|l|}{ Glucose Reactor ( $R_{\text {gluc }}$ ) } \\
\hline Feed Concentration (mM) & HRT (h) & OLR $\left(\mathrm{Kg} \mathrm{COD} / \mathrm{m}^{3} / \mathrm{d}\right)$ \\
\hline 8.3 & 9 & 4.3 \\
\hline 13.8 & 9 & 7.1 \\
\hline 27.7 & 9 & 14.2 \\
\hline \multicolumn{3}{|l|}{ Arabinose reactor $\left(R_{\text {arab }}\right)$} \\
\hline Feed concentration (mM) & HRT (h) & OLR $\left(\mathrm{Kg} \mathrm{COD} / \mathrm{m}^{3} / \mathrm{d}\right)$ \\
\hline 10 & 9 & 4.3 \\
\hline 16.6 & 9 & 7.1 \\
\hline 33.3 & 9 & 14.2 \\
\hline
\end{tabular}

supplemented with trace elements, salts and vitamins according to the procedure described by Stams et al. [33]; yeast extract was added to a final concentration of $0.5 \mathrm{~g} \mathrm{~L}^{-1}$. Medium was reduced with $0.8 \mathrm{mM}$ sodium sulfide $\left(\mathrm{Na}_{2} \mathrm{~S}_{9} 9 \mathrm{H}_{2} \mathrm{O}\right)$ and inoculated with $0.4 \mathrm{~g}$ of granular sludge. Arabinose (13 mM) and glucose $(11 \mathrm{mM})$ were used as the main carbon source. Bottles were incubated in the dark at $70^{\circ} \mathrm{C}$ without shaking. After substrate depletion, a second pulse of $13 \mathrm{mM}$ arabinose or $11 \mathrm{mM}$ glucose was added and incubation extended.

\section{Effect of hydrogen partial pressure}

The effect of hydrogen partial pressure on hydrogen production from arabinose and glucose was investigated in batch mode at $\mathrm{pH}$ 5.5. Two series of batch experiments were performed: in series NHF (no headspace flushing), hydrogen was allowed to accumulate in the gas phase, while in series HF (headspace flushing) hydrogen was removed from the bottles' headspace and replaced by $100 \% \mathrm{~N}_{2}$. All experiments were performed in triplicate and included controls without substrate. Sugars consumption, production of hydrogen gas and soluble fermentation products were monitored. Dissolved hydrogen concentration was calculated using the Henry's law at $70^{\circ} \mathrm{C}: \mathrm{K}_{\mathrm{H}}{ }^{*} \mathrm{Pi}$, where $\mathrm{K}_{\mathrm{H}}$ is the Henry's law constant for hydrogen $\left(8.7 \times 10^{-9} \mathrm{M} / \mathrm{Pa}\right.$ at $\left.70^{\circ} \mathrm{C}\right)$.

\section{Effect of $\mathrm{pH}$}

The effect of $\mathrm{pH}$ on hydrogen production from arabinose and glucose fermentation was studied in two series of batch experiments, one at $\mathrm{pH} 7.0$ and the other at $\mathrm{pH}$ 5.5. Incubation was done at $70^{\circ} \mathrm{C}$ and all the experiments were performed in triplicate. Sugars consumption, formation of hydrogen gas and soluble fermentation products were monitored and dissolved hydrogen concentration was calculated using the Henry's law at $70^{\circ} \mathrm{C}$.

\section{Analytical methods}

Hydrogen concentration in the gas phase was determined by gas chromatography (GC) using a Hayesep Q column (80/100 mesh) and thermal conductivity detector Varian 3300 Gas Chromoatograph, (Varian, Walnut Creek, USA)) with nitrogen (30 mL minute $\left.{ }^{-1}\right)$ as the carrier gas. The injector, detector and column temperatures were 120,170 , and $35^{\circ} \mathrm{C}$ respectively. Methane and carbon dioxide content of the gas phase from batch experiments and EGSB reactors was determined by gas chromatography using a Porapack Q (100 to 180 mesh) column, with helium as the carrier gas at $30 \mathrm{~mL} \mathrm{min-}$ ute $^{-1}$, and a thermal conductivity detector. Temperatures of the detector, injector and oven were 110,110 and $35^{\circ}$ $\mathrm{C}$, respectively. In the EGSB reactors gas flow rate was measured by a Ritter Milligascounter (Dr. Ing. Ritter Apparatebau GmbH, Bochum, Germany). Volatile fatty 
acids (VFA), ethanol, lactic acid, L-arabinose and glucose were determined by high performance liquid chromatography using an HPLC (Jasco, Tokyo, Japan) with a Chrompack column $\left(6.5 \times 30 \mathrm{~mm}^{2}\right)$; sulfuric acid $(0.01$ $\mathrm{N})$ at a flow rate of $0.7 \mathrm{~mL}$ minute ${ }^{-1}$ was used as mobile phase. Column temperature was set at $60^{\circ} \mathrm{C}$. Detection of VFA, lactic acid, ethanol, arabinose, glucose was made sequentially using a UV detector at $210 \mathrm{~nm}$ and a RI detector.

\section{PCR-DGGE}

Representative granular sludge samples were collected from $R_{\text {arab }}$ and $R_{\text {gluc }}$ and stored at $-18^{\circ} \mathrm{C}$. Total genomic DNA was extracted from approximately $500 \mu \mathrm{L}$ of sample by using the FastDNA SPIN kit for soil (Qbiogene, Carlsbad, CA, USA). 16S rRNA gene fragments of approximately $450 \mathrm{bp}$ were amplified for DGGE analysis by PCR using a Taq DNA polymerase kit (Life Technologies, Gaithersburg, MD, USA) using the primer set 954GC-f and 1369-r, as previously described by Nubel et al. [34]. The size of the obtained PCR products was checked by comparison with appropriate size and mass standard (MBI Fermentas, Vilnius, Lithuania), by electrophoresis on an $1 \%(w / v)$ agarose gel and ethidium bromide staining. Gels ran at a constant voltage of $100 \mathrm{~V}$ in an agarose gel electrophoresis system (Mupid-EX, Seraing, Belgium). Nucleic acids were detected using an UV transilluminator (BioRad, Hercules, CA, USA).

DGGE analysis of the amplicons was done by using the DCode system (Bio-Rad). PCR products were electrophoresed in a $0.5 \times$ Trisacetate-EDTA buffer for $16 \mathrm{~h}$ at $85 \mathrm{~V}$ and $60^{\circ} \mathrm{C}$ on polyacrylamide gel $(8 \%)$ containing a linear gradient ranging from $30 \%$ to $60 \%$ denaturant. Silver staining of DGGE gels was performed as previously described [35]. DGGE gels were scanned at 400 dpi and the DGGE profiles compared using the Bionumerics 5.0 software package (Applied Maths, Gent, Belgium). Similarity indices ( $\mathrm{Si}$ ) of the compared profiles were calculated from the densitometric curves of the scanned DGGE profiles by using the Pearson productmoment correlation [36].

\section{Gibb's Free energy calculations}

Standard Gibb's free energy at $25^{\circ} \mathrm{C}\left(\Delta \mathrm{G}^{\circ}\right)$ was calculated using standard Gibb's free energy of formation values $\left(\Delta \mathrm{G}_{\mathrm{f}}^{\mathrm{o}}\right)$ obtained from the literature $[19,20]$ or calculated using the group addition method [19].

\section{Abbreviations}

DGGE: denaturing gradient gel electrophoresis; EGSB: expanded granular sludge bed; NADH: reduced form of nicotinamide adenine dinucleotide; PCR: polymerase chain reaction; $\mathrm{PH}_{2}$ : hydrogen partial pressure.

\section{Acknowledgements}

The financial support from Fundação para a Ciência e Tecnologia (FCT) through the PhD grant SFRH/BD/29823/2006 given to Abreu is gratefully acknowledged. This study also received support from Danish Agency for Science, Technology and Innovation under Bio REF. Project No. 2104-060004.

\section{Author details}

${ }^{1}$ Institute for Biotechnology and Bioengineering, Centre of Biological Engineering, University of Minho, 4710-057 Braga, Portugal. ²Department of Environmental Engineering, Technical University of Denmark, Bygningstorvet 115, DK-2800, Kgs Lyngby, Denmark.

\section{Authors' contributions}

All authors contributed intellectually via scientific discussions during the work and have read and approved the final manuscript. AAA designed the study, executed the experimental work, data interpretation and drafted the manuscript. IA and DK commented on the manuscript and contributed to the design of the study. DZS participated in data interpretation, reaction thermodynamics calculations and reviewed the manuscript. MMA contributed to the design of the study, data interpretation and reviewed the manuscript. All authors read and approved the final manuscript.

\section{Competing interests}

The authors declare that they have no competing interests.

Received: 6 July 2011 Accepted: 13 February 2012

Published: 13 February 2012

\section{References}

1. Ren Nanqi, Guo Wanqian, Liu Bingfeng, Cao Gauangli, Ding Jie: Biological hydrogen production by dark fermentation: challenges and prospects towards scaled-up production. Curr Opin Biotechnol 2011, 22:365-370.

2. Wang $J$, Wan W: Factors influencing fermentative hydrogen production: A review. Int J Hydrogen Energy 2009, 34:799-811.

3. Chieh-Lun Cheng, Yung-Chung Lo, Kuo-Shing Lee, Duu-Jong Lee, ChiuYue Lin, Jo-Shu Chang: Biohydrogen production from lignocellulosic feedstock. Bioresour Technol 2011, 102:8514-8523.

4. Xia LM, Sheng XL: High yield cellulase production by Trichoderma reesei ZU-02 on corncob residues. Bioresour Technol 2004, 91:259-262.

5. Strobel HJ: Evidence for catabolite inhibition in regulation of pentose utilization and transport in the ruminal bacterium selenomonasruminantium. Appl Environ Microbiol 1993, 59:40-46.

6. Abreu AA, Alves Jl, Pereira MA, Karakashev D, Alves MM, Angelidaki I: Engineered heat treated methanogenic granules: a promising biotechnological approach for extreme thermophilic biohydrogen production. Bioresour Technol 2010, 101:9577-9586.

7. Jones DT, Woods DR: Acetone-butanol fermentation revisited. Microbiol Rev 1986, 50:484-524

8. Turcot J, Bisaillon A, Hallenbeck PC: Hydrogen production by continuous cultures of Escherchia coli under different nutrient regimes. Int J Hydrogen Energy 2008, 33:1465-1470.

9. Verhaart MRA, Bielen AAM, van der Oost J, Stams AJM, Kengen SWM: Hydrogen production by hyperthermophilic and extremely thermophilic bacteria and archaea: mechanisms for reductant disposal. Environ Technol 2010, 31:993-1003.

10. Valdez-Vazquez I, Poggi-Varaldo HM: Hydrogen production by fermentative consortia. Renew Sustain Energy Rev 2011, 13:1000-1013.

11. Stams AJM: Metabolic interactions between anaerobic-bacteria in methanogenic environments. Antonie Van Leeuwenhoek 1994, 66:271-294.

12. Hawkes FR, Dinsdale R, Hawkes DL, Hussy I: Sustainable fermentative hydrogen production: challenges for process optimisation. Int J Hydrogen Energy 2002, 27:1339-1347.

13. van Groenestijn JW, Hazewinkel JHO, Nienoord M, Bussmann PJT: Energy aspects of biological hydrogen production in high rate bioreactors operated in the thermophilic temperature range. Int J Hydrogen Energy 2002, 27:1141-1147.

14. Lu JQ, Gavala HN, Skiadas IV, Mladenovska Z, Ahring BK: Improving anaerobic sewage sludge digestion by implementation of a hyperthermophilic prehydrolysis step. J Environ Manage 2008, 88:881-889. 
15. Kleerebezem R, van Loosdrecht MCM: Mixed culture biotechnology for bioenergy production. Curr Opin Biotechnol 2007, 18:207-212.

16. Temudo MF, Kleerebezem $\mathrm{R}$, van Loosdrecht $\mathrm{M}$ : Influence of the $\mathrm{pH}$ on (open) mixed culture fermentation of glucose: a chemostat study. Biotechnol Bioeng 2007, 98:69-79.

17. Nanqi Ren, Aijie Wang, Guangli Cao, Jifei Xu, Lingfang Gao: Bioconversion of lignocellulosic biomass to hydrogen: potential and challenges. Biotechnol Adv 2009, 27:1051-1060.

18. Willquist $K$, Zeidan AA, van Niel EWJ: Physiological characteristics of the extreme thermophile Caldicellulosiruptor saccharolyticus: an efficient hydrogen cell factory. Microb Cell Fac 2010, 9:89.

19. Mavrovouniotis ML: Estimation of standard Gibbs energy changes of biotransformations. J Biol Chem 1991, 266:14440-14445.

20. Thauer RK, Jungermann K, Decker K: Energy-Conservation in Chemotropic Anaerobic Bacteria. Bacteriol Rev 1977, 41:100-180.

21. Altaras NE, Etzel MR, Cameron DC: Conversion of sugars to 1,2propanediol by Thermoanaerobacterium thermosaccharolyticum HG-8. Biotechnol Prog 2001, 17:52-56.

22. Wu KJ, Saratale GD, Lo YC, Chen WM, Tseng ZJ, Chang MC, Tsai BC, Su A, Chang JS: Simultaneous production of 2,3-butanediol, ethanol and hydrogen with a Klebsiella sp strain isolated from sewage sludge. Bioresour Technol 2008, 99:7966-7970.

23. Kotay SM, Das D: Microbial hydrogen production with Bacillus coagulans IIT-BT S1 isolated from anaerobic sewage sludge. Bioresour Technol 2007, 98:1183-1190.

24. Karadag D, Puhakka JA: Direction of glucose fermentation towards hydrogen or ethanol production through on-line $\mathrm{pH}$ control. Int $\mathrm{J}$ Hydrogen Energy 2010, 35:10245-10251.

25. Karadag D, Puhakka JA: Effect of changing temperature on anaerobic hydrogen production and microbial community composition in an open-mixed culture bioreactor. Int J Hydrogen Energy 2010, 35:10954-10959.

26. Kotay SM, Das D: Microbial hydrogen production from sewage sludge bioaugmented with a constructed microbial consortium. Int I Hydrogen Energy 2010, 35:10653-10659.

27. Shaw AJ, Hogsett DA, Lynd LR: Identification of the [FeFe]-hydrogenase responsible for hydrogen generation in Thermoanaerobacterium saccharolyticum and demonstration of increased ethanol yield via hydrogenase knockout. J Bacteriol 2009, 191:6457-6464.

28. Kengen SWM, Stams AJM, deVos WM: Sugar metabolism of hyperthermophiles. FEMS Microbiol Rev 1996, 18:119-137.

29. Adams MWW: The metabolism of hydrogen by extremely thermophilic sulfur-dependent bacteria. FEMS Microbiol Rev 1990, 75:219-237.

30. van Niel EWJ, Claassen PAM, Stams AJM: Substrate and product inhibition of hydrogen production by the extreme thermophile, Caldicellulosiruptor saccharolyticus. Biotechnol Bioeng 2003, 81:255-262.

31. Schafer T, Schonheit P: Pyruvate metabolism of the hyperthermophilic Archaebacterium pyrococcus-furiosus - acetate formation from acetyl-coa and Atp synthesis are catalyzed by an acetyl-coa synthetase (Adp forming). Arch Microbiol 1991, 155:366-377.

32. Schroder C, Selig M, Schonheit P: Glucose fermentation to acetate, co2 and $\mathrm{h}-2$ in the anaerobic hyperthermophilic Eubacterium thermotogamaritima - involvement of the Embden-Meyerhof Pathway. Arch Microbio 1994, 161:460-470

33. Stams AJM, Vandijk JB, Dijkema C, Plugge CM: Growth of syntrophic propionate-oxidizing bacteria with fumarate in the absence of methanogenic bacteria. Appl Environ Microbiol 1993, 59:1114-1119.

34. Nubel U, Engelen B, Felske A, Snaidr J, Wieshuber A, Amann Rl, Ludwig W Backhaus H: Sequence heterogeneities of genes encoding 165 rRNAs in Paenibacillus polymyxa detected by temperature gradient gel electrophoresis. J Bacteriol 1996, 178:5636-5643.

35. Sanguinetti $C J$, Neto ED, Simpson AJG: Rapid silver staining and recovery of pcr products separated on polyacrylamide gels. Biotechniques 1994 17:914-

36. Hane BG, Jager K, Drexler HG: The Pearson Product-Moment CorrelationCoefficient Is better suited for identification of DNA fingerprint profiles than band matching algorithms. Electrophoresis 1993, 14:967-972.

doi:10.1186/1754-6834-5-6

Cite this article as: Abreu et al:: Biohydrogen production from arabinose and glucose using extreme thermophilic anaerobic mixed cultures. Biotechnology for Biofuels 2012 5:6.

\section{Submit your next manuscript to BioMed Central and take full advantage of:}

- Convenient online submission

- Thorough peer review

- No space constraints or color figure charges

- Immediate publication on acceptance

- Inclusion in PubMed, CAS, Scopus and Google Scholar

- Research which is freely available for redistribution

Submit your manuscript at www.biomedcentral.com/submit
Biomed Central 